\title{
ANALISIS PENILAIAN TENGAH SEMESTER MENGGUNAKAN SISTEM CBT PADA MATA PELAJARAN MATEMATIKA DI SMK ISLAM PERTI JAKARTA
}

\author{
M. Ardiansyah \\ Universitas Indraprasta PGRI, Indonesia \\ m.ardiansyah_unindra@yahoo.co.id
}

\begin{abstract}
Received: 08 Oktober 2020 Penelitian ini merupakan penelitian deskriptif yang bermaksud untuk Revised: 28 November 2020 memperoleh gambaran tentang Analisis penilaian tengah semester (PTS) Accepted: 18 Desember 2020 dengan menggunakan sistem CBT (Computer Based Test) mata pelajaran matematika Peserta didik. Penelitian ini dilakukan di SMK Islam Perti Jakarta, Jalan tawakal raya No.99 Kelurahan Tomang Kecamatan Grogol Petamburan Jakarta Barat. Subjek penelitian sebanyak 30 orang peserta didik yang diambil secara purposive random samping. Adapun simpulan dari penelitian ini antara lain: 1) Penggunaan CBT pada penilaian tengah semester mata pelajaran mtematika di SMK Islam Perti Jakarta sangat bermanfaat, terutama dari segi efisiensi penggunaan kertas menjadi ujian berbasis CBT. 2) Penggunaan CBT dalam pembelajaran matematika khususnya mampu meningkatkan minat kepada peserta didik karena tampilan soal matematika yang cukup menarik dan dikerjakan melalui Handphone android masing-masing peserta didik, sehingga hasil ujian PTS matematika ada peningkatan. 3) Penggunaan CBT untuk PTS ditemukan banyak permasalahan yang dihadapi oleh peserta didik, diantaranya koneksi internet kurang optimal, mengakibatkan pengerjaan soal matematika Peserta didik menjadi terhambat. Selain itu, kendala-kendala teknis yang terjadi pada saat ujian PTS berlangsung seperti tidak muncul soal, waktu pengerjaan yang tidak sesuai, gambar tabel/simbol matematika yang tidak tampil di layar handphone peserta didik, lupa username dan password sehingga membuat pengerjaan ujian PTS matematika Peserta didik menjadi terganggu dan tidak maksimal.
\end{abstract}

Keywords: Penilaian tengah semester; PTS; Computer based test; CBT; Matematika

(*) Corresponding Author: $\quad$ Ardiansyah, m.ardiansyah_unindra@yahoo.co.id, +62 87888392696

How to Cite: Ardiansyah, M. (2021). Analisis Penilaian Tengah Semester Menggunakan Sistem CBT Pada Mata Pelajaran Matematika Di SMK Islam Perti Jakarta. Research and Development Journal of Education, 7 (1), 29-38.

\section{INTRODUCTION}

Di era revolusi 4.0 seperti sekarang ini perkembangan teknologi informasi dan komunikasi menimbulkan banyak sekali perubahan di berbagai lini kehidupan, salah satunya adalah dunia pendidikan. Dampak yang ditimbulkan perkembangan ini memiliki sisi yang positif maupun negatif tergantung siapa pengguna yang akan menggunakan teknologi tersebut. Penguasaan teknologi dengan baik dan benar diperlukan pengetahuan yang cukup memadai sehingga kita dapat memanfaatkannya dalam menghadapi tuntutan dunia global yang syarat dengan banyak persaingan (Nasrulloh \& Ismail, 2018). Perkembangan teknologi informasi di dalam dunia kependidikan yakni penilaian tengah semester (PTS) berbasis android yang pertama kali dirintis oleh SMK Islam Perti adalah pada tahun 2017 dan telah terkenal dengan CBT SMK Islam Perti. 
Tes ini memiliki kemiripan seperti tes pada umumnya yaitu memberikan soal tes kepada peserta didik dengan batas waktu yang sudah ditentukan. Adapun yang membedakan dari jenis tes ini adalah pada aplikasi penggunaannya yang tidak menggunakan kertas, baik untuk naskah soal maupun pada lembar jawabannya. Sistem skoring atau koreksi langsung tampil di komputer admin sekolah. Jika biasanya peserta dengan mudah melihat point soal pertama hingga akhir, sistem CBT tentunya berbeda dari yang biasanya. Hal ini senada dengan Lidya Wati et al (2018) mengatakan Pada umumnya sekolah-sekolah dalam pelaksanaan UTS menggunakan sistem ujian berbasis kertas (paper based test) akan tetapi sudah beralih mengimplementasikan CBT pada pelaksanaan ujian PTS di SMK.

Ujian PTS dengan penggunaan CBT merupakan transisi dari teknik ujian yang berawal dari ujian konvensional atau berbasis kertas, diperlukan perbandingan nilai validitasi terhadap kedua versi tersebut. Namun, tidak ada bukti yang kuat untuk memutuskan bahwa ujian CBT menghasilkan hasil yang kurang valid. Pendidikan sekarang ini yang memanfaatkan teknologi terpusat merupakan program dari pemerintah dalam rangka membangun mutu dan kualitas pendidikan di Indonesia, mengingat banyak fenomena kecurangan dan kebocoran pada saat mengerjakan soal Ujian berbasis kertas di tahun sebelumnya. Hal lain yang melatar belakangi penggunaan teknologi dalam Ujian PTS yakni mengurangi biaya/anggaran dana ujian dengan menghapus distribusi soal dan lembar jawaban sebagai media PTS.

Computer based testing merupakan ujian yang dikerjakan di komputer sehingga tidak memerlukan kertas, pena maupun pensil untuk menjawab setiap pertanyaannya. Naskah Soal terdapat di komputer dan lembar jawabannya juga disediakan di komputer sehingga peserta didik hanya mengklik jawaban yang benar atau tinggal mengetik jika terdapat pertanyaan uraian. Computer based test seperti ini cukup banyak diaplikasikan di berbagai bidang, tidak terkecuali bidang pendidikan, umumnya dipakai untuk menentukan berapa nilai tertinggi seorang peserta didik atau mahasiswa dalam menguasai mata pelajaran atau mata kuliah (Lidya et al., 2018).

Ujian PTS menjadi urgency tersendiri yang dapat menentukan tingkat keberhasilan seseorang Peserta didik yang dicantumkan dalam Kartu hasil Studi (KHS) selama sekitar 3 bulan menempuh pendidikan. Dalam beberapa tahun terakhir, pelaksanaan Ujian PTS di SMK Islam Perti dibagi menjadi dua yaitu diawali dengan PTS berbasis kertas yang dikenal dengan istilah PBT (Paper Based Test). Pelaksanaan PTS dengan sistem PBT dinilai memiliki banyak sekali kekurangan, salah satu diantaranya yaitu Pendidik terkadang kurang teliti dalam hal penilaian sehingga terjadi kesalahan dalam menilai hasil Ujian Peserta didik. Sistem manual (PBT) menjadi kendala dalam melaksanakan ujian seperti pengadaan soal, waktu pemeriksaan dan waktu pengumuman (Suryadi, 2018). Instrumen tes yang bersifat konvensional tentu saja kurang inovatif, efektif, efisien, membosankan dan tidak up to date. Instrumen tes yang berbasis komputer merupakan alat yang cukup menjanjikan untuk dijadikan tolak ukur sebuah pendidikan. Instrumen ini menawarkan potensi yang cukup tinggi dan nilai tambah dibandingkan dengan tes kertas dan pensil.

Pendidik harus dapat memanfaatkan apapun jenis perkembangan teknologi sekarang ini untuk melakukan ujian berbasis komputer/android. Kekurangan Ujian PTS sistem PBT diantaranya adalah secara teknis mulai dari kertas untuk jawaban peserta ujian yang tidak diperbolehkan rusak, robek hingga jawaban soal ujian yang disebar di setiap kelas menyebabkan peserta didik sebagai peserta ujian menjadi tidak fokus dan tidak jarang menurunkan minat dan motivasi dalam diri peserta didik. Hal ini berpengaruh pada keadaan psikologi Peserta didik ketika mengerjakan soal PTS. Untuk mengatasi permasalahan ini, SMK Islam Perti mulai menerapkan Ujian PTS berbasis komputer atau dikenal dengan CBT (Computer Based Test). 
PTS adalah sistem pelaksanaan ujian yang dilaksanakan setiap satu kali dalam semester dengan menggunakan handphone android masing-masing Peserta didik sebagai media ujiannya. Penyelenggaraan PTS SMK Islam Perti Jakarta pertama kali dilaksanakan pada tahun 2017 secara online kepada seluruh Peserta didik yang sekolah di SMK Islam Perti. Hasil pelaksanaan ujian PTS dengan sistem CBT terhadap hasil ujian PTS matematika Peserta didik tersebut cukup sukses dan mendorong literasi Peserta didik terhadap Teknologi Informasi dan Komunikasi agar semakin meningkat. Pada tahap selanjutnya, rintisan penyempurnaan Aplikasi dilaksanakan ditahun 2018 dengan Peserta didik sebanyak 802 Peserta didik kelas X, XI, dan XII.

Pada Awalnya ujian PTS dilaksanakan dengan menggunakan sistem semionline yaitu soal dikirim dari admin sekolah secara online melalui jaringan (sinkronisasi) ke semua Peserta didik, kemudian Peserta didik mengerjakan soal ujian tersebut secara offline. Selanjutnya hasil ujian PTS matematika otomatis dikirim oleh Admin sekolah dan dapat dilihat secara langsung oleh Peserta didik nilai yang didapatkannya.

Berdasarkan uraian di atas, maka salah satu upaya yang dapat dilakukan untuk mengatasi permasalahan tersebut yaitu mengembangkan paket tes dalam berpikir tingkat tinggi yang dapat dikemas dengan memanfaatkan gadget/handphone sebagai alat untuk menyimpan, mengolah dan memproses tes yang telah dibuat untuk digunakan dalam melakukan penilaian kepada Peserta didik. Kadir (2015) menyatakan ada beberapa pedoman untuk para penulis soal dalam membuat butir soal yang dapat menuntut pendidik untuk berpikir tingkat tinggi, yaitu materi yang ditanyakan diukur dengan sikap Peserta didik, yaitu menganalisis, mengevaluasi, dan mencipta. Setiap butir soal selalu diberikan stimulus yang dapat berbentuk sumber bacaan sebagai informasi seperti: grafik, gambar, contoh, rumus, tabel, daftar simbol, atau rekaman suara.

Penelitian yang relevan yaitu penelitian yang dilakukan oleh Novrianti (2014), tentang Pengembangan Computer Based Testing (CBT) sebagai sala satu alternatif teknik penilaian dari hasil belajar. Hasil penelitiannya menunjukkan CBT sangat layak digunakan sebagai media alternatif untuk memecahkan sebuah permasalahan dari pelaksanaan evaluasi pembelajaran. Selain itu, penggunaan system CBT harus mempunyai fasilitas yang lengkap. Sesuai dengan pernyataan Sudibyo (2011), mengatakan bahwa Untuk dapat memanfaatkan teknologi informasi dibutuhkan setidaknya tiga komponen utama, yaitu perangkat keras (hardware), perangkat lunak (software), dan manusia (brainware). Computer based test (CBT) has emerged as one of the most recent "innovative" approaches to assessment conducted by states. CBT has been hailed as the answer to cheaper and faster delivery of tests for state and district level assessments. in part as a follow-up to a similar exploration that took place in the early 2000s when only a few states began to develop and apply CBT to their state assessment (Thurlow et al., 2010).

Matematika dianggap pelajaran yang cukup sulit oleh sebagian peserta didik, bahkan ada peserta didik yang merasa bosan, takut, dan tidak tertarik pada pembelajaran matematika. Kurangnya rasa ingin tahu dan minat belajar yang terdapat dalam diri peserta didik dan kecenderungan peserta didik belajar hanya dengan menghafal rumus saja tanpa mengetahui dari mana rumus diperoleh serta sikap peserta didik yang terkadang kurang jujur dalam belajar merupakan penyebab yang mengakibatkan hasil belajar yang dicapai peserta didik belum optimal. Matematika menjadi momok yang menakutkan bagi para peserta didik terutama disaat ulangan atau ujian sekolah (Lutvaidah, 2016). Mata pelajaran matematika masih menjadi konsentrasi penting bagi sekolah. Pendidk harus bisa mengajarkan peserta didik pelajaran matematika dengan baik dan benar. Pendidik semaksimalmungkin untuk membantu peserta didik dalam proses belajar matematika, oleh sebab itu pendidik perlu tahu bagaimana sebenarnya jalan atau proses matematika agar bisa dipahami atau dikuasai oleh peserta didik (Sutawidjaja \& Afgani, 2015). Hal ini 
dikarenakan keberhasilan dari seorang Peserta didik dalam memperoleh nilai tinggi pembelajaran matematika dalam ujian PTS juga akan meningkatkan nama baik dan prestasi pribadi khususnya, untuk sekolah secara tidak langsung dalam bidang akademik. Meskipun yang mengerjakan soal matematika tidak $100 \%$ mendapatkan nilai maksimal, akan tetapi minimal Peserta didik mendapatkan rata-rata nilai ketuntasan minimal dalam pelajaran matematika khususnya.

Matematika merupakan mata pelajaran yang dimana pelaksanaan ujian sistem CBT ini banyak memunculkan respon dan reaksi Peserta didik itu sendiri, diantaranya peserta didik diharapkan akan mampu mencapai indikator ketercapaian dalam aspek kognitif maupun keterampilannya. Maka, proses evaluasi dalam pelajaran matematika ini menekankan analisis yang berhubungan dengan potensi intelektual atau pengetahuannya. Namun, dalam hal ini urgency penerapan CBT matematika hanya sebagai jalan mudah dalam mengolah data hasil jawaban Peserta didik agar diperoleh hasil penelitian yang lebih tepat dan akurat. Matematika merupakan kemampuan peserta didik dalam menggunakan, menafsirkan, dan merumuskan matematika dalam berbagai konteks. Tidak terkecuali didalamnya bernalar secara matematis dan menggunakan konsep, prosedur, dan alat matematika untuk dapat menjelaskan serta memprediksi fenomena (Putra, 2012).

Demi menunjang suksesnya ujian PTS serta mewujudkan generasi milenial yang siap menghadapi tantangan era modern dimasa yang akan datang, SMK Islam Perti menggalakkan program ujian online diberbagai jenis test setiap pembelajaran di kelas. Salah satunya yakni Ulangan Harian atau Quis berbasis CBT. Ini merupakan hal baru yang dialami Peserta didik dalam pengambilan nilai evaluasi terkait mata pelajaran matematika. Computer based test (CBT) is effective solution for mass education evaluation. Variety of e-assessment approaches and systems have been developed in recent times, yet lack of flexible timing functionality to automatically log off candidates upon expiration of allotted time, result integrity comprise, stand-alone deployment, lack of flexibility, robustness and scalability as well as human error are major limitations of the existing platforms. In this paper, a web based online examination system is developed to address these aforementioned drawbacks. The system is designed to facilitate the examination processes and manage challenges surrounding the conduct of examination, auto-submission, auto-marking and examination result report (Fagbola et al., 2013).

Dengan demikian, sistem penilaian yang baru dilaksanakan ini memunculkan masalah baru pula bagi setiap Peserta didik terutama psikologi dalam meningkatkan minat dan motivasi belajar matematika Peserta didik yang menunjukkan belum begitu siap beradaptasi dengan program tersebut. Hal ini diperlukan pengamatan dan kajian lebih dalam mengenai berbagai dampak sistem CBT terhadap minat dan motivasi belajar Peserta didik dalam mata pelajaran matematika. The results of the study show the priority of PPT over CBT with 01 degree of difference at $p<0.05$. Using ANOVA, the findings revealed that computer based test familiarity and attitude towards computer had no significant influence on the students' performance in computerized test. Additionally, participants showed more preference on test features presented on the computer test (Hosseini et al., 2014).

Ujian Penilaian Tengah Semester (PTS) di SMK Islam Perti penulis hanya membatasi penelitian ini pada ruang lingkup penilaian dengan menggunakan Computer Based Test (CBT) pada mata matematika. Kompetensi inti dalam pendidikan hanya mampu terpenuhi oleh butiran kompetensi dasar (KD) yang ada pada mata pelajaran matematika yakni lebih menekankan kepada penela ahan soal matematika dan analisis serta mencari jawaban dari permasalahan yang diberikan pendidik. Selain capaian kognitif dan kreatifitas, Peserta didik diharapkan memiliki karakter dan akhlak yang baik pula. Namun dalam penilaian menggunakan sistem CBT hanya sekedar mengambil hasil 
capaian pembelajaran kognitif saja. Sehingga nilai yang diperoleh belum mencakup semua aspek.

\section{METHODS}

Penelitian ini merupakan penelitian deskriptif yaitu penelitian yang berusaha mendeskripsikan dengan maksimal suatu peristiwa, kejadian yang terjadi pada saat sekarang (Sudjana, 2013). Penelitian ini bermaksud untuk memperoleh gambaran apa adanya dari fenomena yang berada dalam konteks penelitian yaitu tentang Analisis penilaian tengah semester dengan menggunakan sistem CBT (Computer Based Test) mata pelajaran matematika Peserta didik. Penelitian ini dilakukan di SMK Islam Perti Jakarta, Jalan tawakal raya No.99 Kelurahan Tomang Kecamatan Grogol Petamburan Jakarta Barat. Subjek penelitian sebanyak 30 orang peserta didik yang diambil secara purposive random samping. Instrumen utama dalam penelitian ini adalah peneliti sendiri, sebagaimana diungkapkan oleh Harun Al-Rasyid, (2013) bahwa penelitian kualitatif memiliki keutamaan diantaranya peneliti sendiri sebagai instrumen utama untuk mendatangi secara langsung di lokasi tempat sumber data, mengimplementasikan data yang dikumpulkan dalam penelitian ini lebih cenderung dalam bentuk deskripsi, peneliti merupakan alat penelitian yang utama. Teknik pengumpulan data penelitian ini melalui: (1) dokumentasi, (2) wawancara, dan (3) studi perpustakaan.

\section{RESULTS \& DISCUSSION}

\section{Results}

Pelaksanaan ujian PTS dengan menggunakan system CBT (Computer Based Test) berlangsung sesuai jadwal yang telah dibuat oleh wakil kurikulum SMK Islam Perti.

\begin{tabular}{|c|c|c|c|c|c|c|c|c|c|c|}
\hline \multirow{2}{*}{ Ko } & \multirow{2}{*}{$\begin{array}{c}\text { HRA } \\
\text { TRVaSUL }\end{array}$} & \multirow{2}{*}{ VAKTU } & \multicolumn{8}{|c|}{ RLTAPELAJARAWIKELAS } \\
\hline & & & XAK & $\mathrm{X} / \mathrm{P}$ & $\mathrm{XNN}$ & Y glas & g्llAP & хмм & XIAK & घI $R P$ \\
\hline \multirow{5}{*}{1} & & $0630 \cdot 073$ & Pendidgara & Fend Agens & Pend. Aygra & Pend Agnas & Pend Agana & Pend Agara & Fend Agena & Pend._lyara \\
\hline & Sein & $6039-1083$ & Seribudala & StriBudaja & SeriButa & Prel. AK Lenbaya & OTKKepeyarian & Deain Gitsfention & 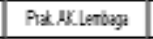 & OTRP Keusuge \\
\hline & $3-5 e 20$ & $(8.3) \cdot \cos .1)$ & Istickat & stiahat & Istirakat & & & & stivathe & Istineat \\
\hline & & 19100.1000 & AhatroiDasa & Krespondensi & Fis & Prodik Kaditho & Produkesfiz:My & Frodikhastuov & PidagpidarVI & PresayadanKU \\
\hline & & $1000 \cdot 1100$ & Sindeo' Kon Dgits] & Simulask Kon Dighd & SinulebtKan Dight & An Pipl. & OTRKesaygn & $\cdot$ & - & $\cdot$ \\
\hline \multirow{5}{*}{2} & & $0639-0034$ & Natentia & Mannalita & Natentika & Matenatia & Mandika & Whamtin & Manalia & Natentia \\
\hline & Seba & 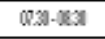 & Sejardhotonesit & Sęarkthdoresá & 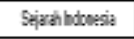 & Konpder Abstasi & OTXKhostficubloter & 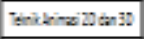 & 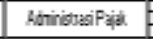 & 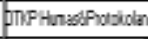 \\
\hline & $22 \operatorname{sen} 20$ & $[8.3)-00.0]$ & Istinatat & btiahat & Istrakat & lstiahat & Istirahst & & stiraht: & Istirekat \\
\hline & & $1900 \cdot 1000$ & B.Atab & B.A.d & B. hab & B.Aab & B. Arb & B. Aab & B.Arb & B. $A a b$ \\
\hline & & $1000 \cdot 100$ & Burnoribisic & BlononiBinis & Stane- lompty & Pide AK Jasalogyng & - & - & Alutansikevangn & $\cdot$ \\
\hline \multirow{5}{*}{3} & & 0630003 & B Bhdoresia & B. ndonesia & B Bhoresá & B. hudonesis & B.honesit & B. Bdonesia & B. hidonesia & Bhoresá \\
\hline & Rlabu & $0830-063$ & Periesor & Pripsor & Penizor & Periason & Peniess & Peijasor & Korpten Alinatasi & OTRPSapus \\
\hline & $2 \operatorname{sen} 20$ & $(8.3)-(10.9)$ & Istiakat & stizhat: & Istrakat & stimatat & Istirahst & & Istirahat: & Istiratat \\
\hline & & 1900.1000 & Bhogis & B. bygirs & B hogis & B. hogirs & B. hogis & B logis & B. hggis & Blingis \\
\hline & & $1000 \cdot 1100$ & Athinisuail|hun & Adrinstrailunn & Dardeain $6 \pi^{\prime}$ & - & - & - & - & $\cdot$ \\
\hline \multirow{6}{*}{4} & & (2630-0037 & $\mathrm{PA}$ & $\mathrm{PA}$ & Inis & Abatersikeurgyan & DTKSapres & $=$ & 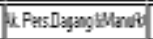 & chelkpegnàa \\
\hline & & $0,30-083$ & $\mathrm{POI}$ & $\mathrm{PD}$ & PoI & $\mathrm{PQ}$ & PX & por & $\mathrm{PQ}$ & $\mathrm{POI}$ \\
\hline & Kanis & $(8.3)-10.11)$ & Istiakat & stiats: & binte & & & & Istiraht: & Istickat \\
\hline & $24 \operatorname{sep} 20$ & 1900.0000 & Eliaforosi & Teinologifeticritore & Aemgenterer & & & & - & . \\
\hline & & $1000 \cdot 1100$ & PetratanDaser & Kescipan & Iontetelinger $2 x$ & & & & - & . \\
\hline & & $100 \cdot 200$ & Spovibleen & - & $\cdot$ & & & & - & . \\
\hline
\end{tabular}

Sumber : Peneliti (2020)

Gambar 1.

Jadwal PTS Ganjil SMK Islam Perti 
Ujian PTS dibagi menjadi rata-rata 4 mata pelajaran setiap harinya, tergantung jurusan yang diambilnya dimulai dari pagi pukul 06.30 sampai dengan siang pukul 11.00 WIB. Setiap PTS 1 mata pelajaran dikasih waktu 1 jam untuk mengerjakan. Dalam hal ini, peneliti memperoleh kesempatan untuk observasi secara langsung pada saat ujian CBT berlangsung.
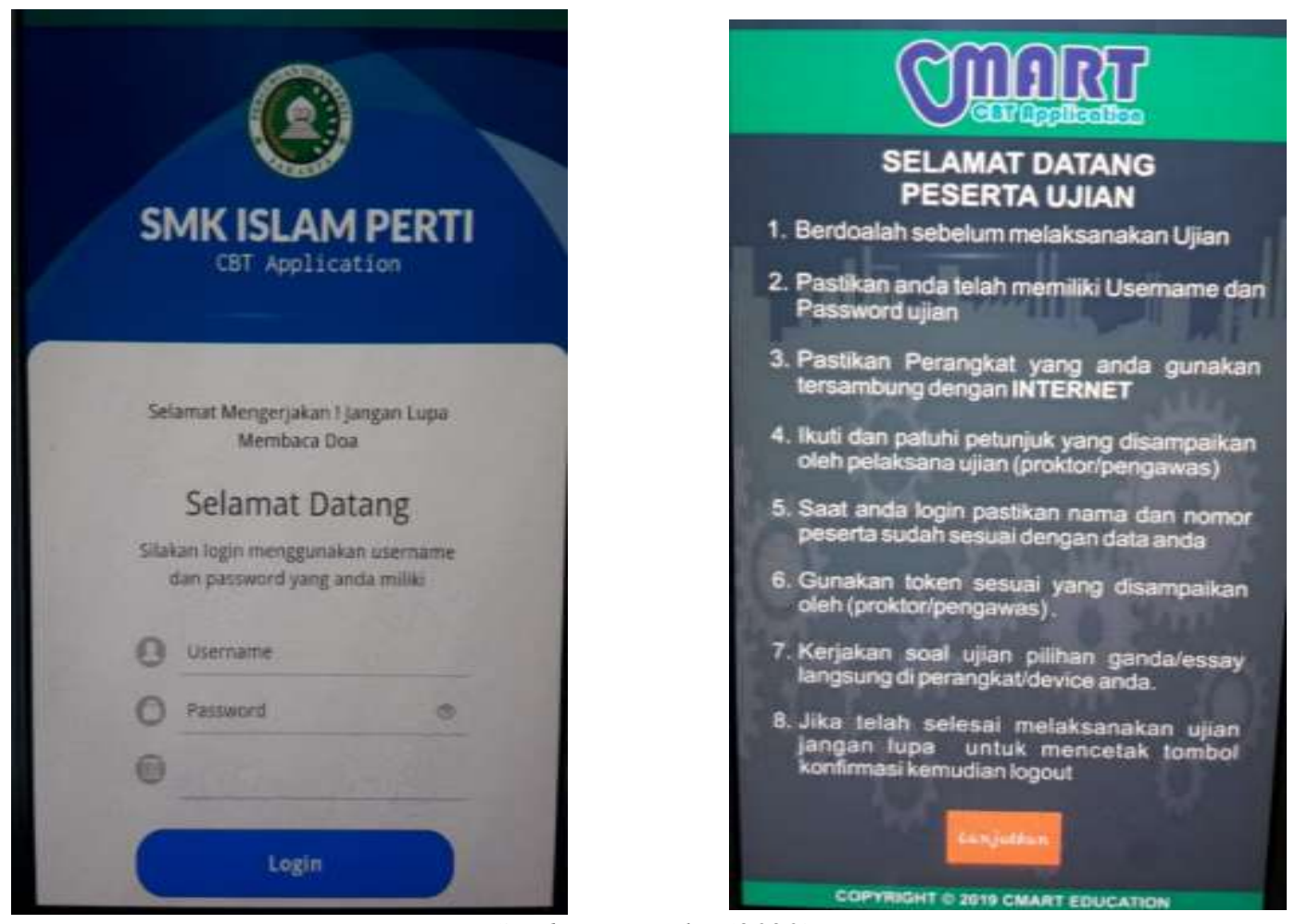

Sumber : Peneliti (2020)

Gambar 2.

Tampilan Awal Aplikasi CBT Aplication SMK Islam Perti Jakarta

Observasi yang dilakukan pada Selasa, 22 September 2020 diawali dengan bel masuk yang menandakan bahwa Peserta didik harus menyiapkan handphone android masing-masing untuk melaksanakan ujian PTS berbasis CBT. Peserta didik diharapkan mempersiapkan handphone dan charger serta mengisi paketan internet. Ujian masingmasing dilaksanakan dirumah dan untuk melakukan ujian dengan menggunakan data paket internet atau menyambungkan WIFI / Hotspot. 


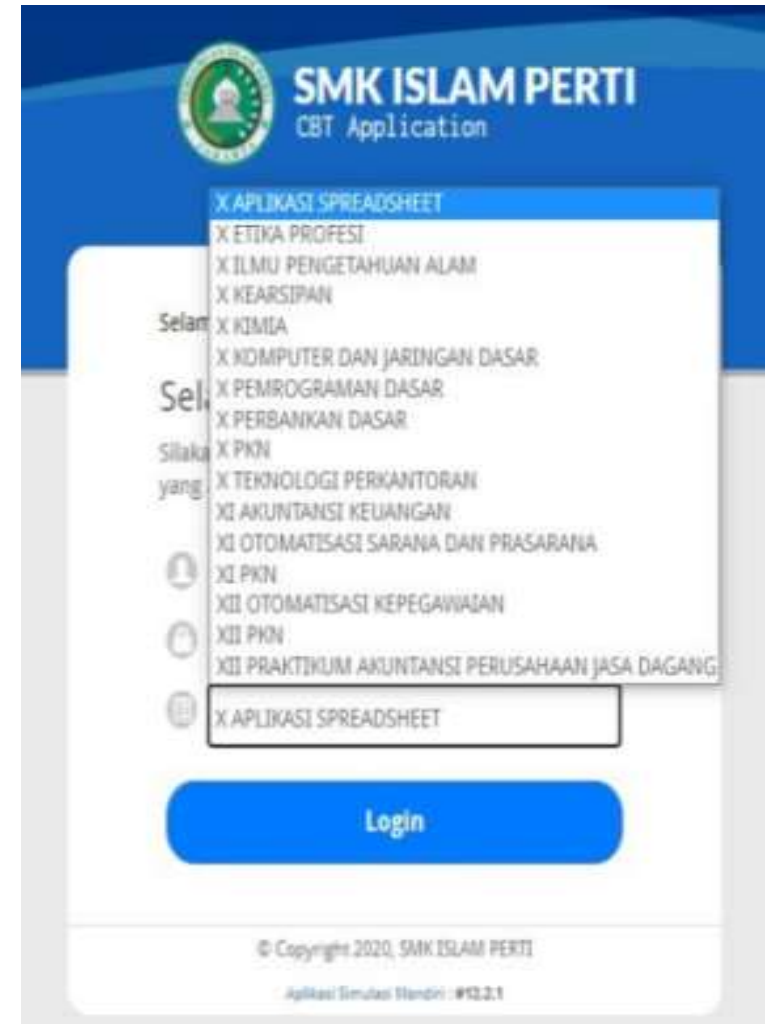

Sumber : Peneliti (2020)

\section{Gambar 3.}

Pilihan mata pelajaran PTS dengan sistem CBT

Setelah koneksi dari server admin sekolah tersambung, barulah Peserta didik diarahkan untuk mengerjakan ujian sesuai prosedur pelaksanaan ujian dengan basis CBT dan dipantau oleh walikelas selama PTS matematika berlangsung. Walikelas sebisa mungkin menciptakan suasana yang tenang agar membuat Peserta didik mengerjakan butiran soal PTS nyaman dan serius.

\section{Discussion}

Ditengah berlangsungnya ujian dengan system CBT, terdapat banyak Peserta didik yang mengalami kendala teknis dalam hal jaringan, battery Handphone habis, adapula kendala koneksi akibat jaringan wifi yang tidak menjangkau Handphone para peserta ujian. Hal ini membuat sebagian Peserta didik yang mengalami kendala dan harus melakukan sesuatu agar dapat menyelesaikan PTS, karena tanpa koneksi jaringan internet, Peserta didik tidak dapat menyelesaikan butir soal yang telah diberikan dengan baik dan lancar. 

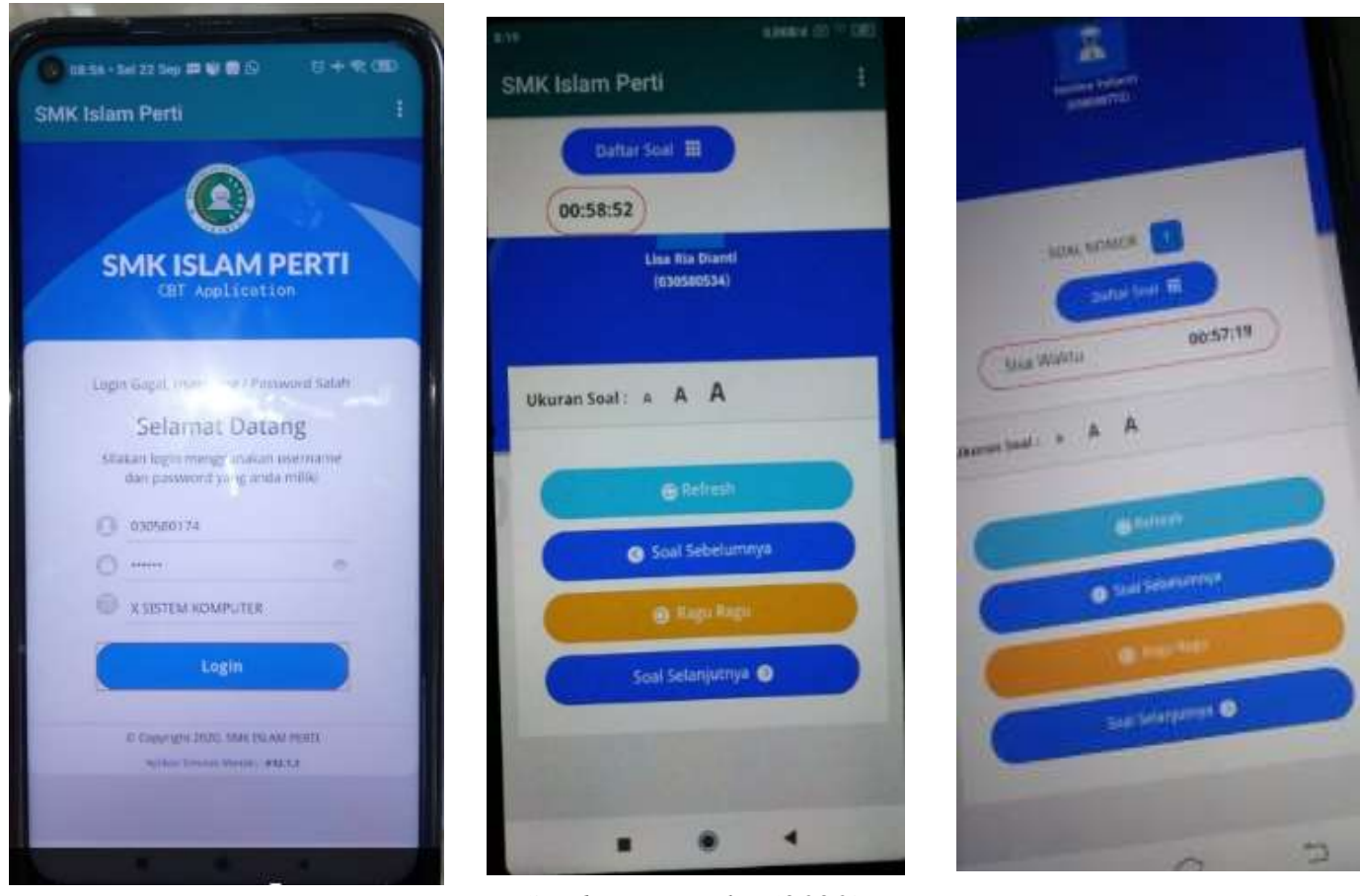

Sumber : Peneliti (2020)

Gambar 3.

Berbagai macam permasalahan Peserta didik pada saat PTS sistem CBT

Peneliti menemukan berbagai macam permasalahan pada saat Peserta didik mengerjakan soal PTS dengan system CBT. Permasalahan yang ditemukan antara lain : 1) Ada beberapa Peserta didik yang tidak bisa login karena permasalahan teknis yaitu ada penginputan username/password yang salah sehingga membuat peserta didik tidak dapat masuk di ujian. 2) Peserta didik yang tidak mendapatkan sinyal jaringan internet agar tersambung kembali ke halaman soal pengerjaan. 3) Peserta didik yang tidak berhasil menyambungkan jaringan hingga waktu pengerjaan habis. Akhirnya Peserta didik tersebut harus mengikuti ujian susulan di minggu berikutnya. 4) di layar Handphone Peserta didik tidak muncul soal, hanya jawabannya saja yang tertera sehingga membuat Peserta didik menjawab asal-asalan 5) Pada soal matematika, banyak soal yang tidak terbaca di Handphone Peserta didik, karena format rumus, gambar, table harus disesuaikan dengan format yang bisa terbaca di handphone Peserta didik itu sendiri. 6) waktu pengerjaan yang seharusnya 60 menit, terkadang ada Peserta didik yang hanya mempunyai waktu 15 menit, 30 menit atau bahkan lebih dari waktu normal seperti 120 menit.

Kendala-kendala yang demikian menyebabkan semangat Peserta didik dalam menghadapi ujian PTS akan menurun dengan tiba-tiba. berbeda dengan ujian berbasis kertas, jika waktu hampir habis, Peserta didik akan mengerjakan ujian semampunya sehingga akan tetap dianggap mengikuti ujian hingga akhir waktu yang ditentukan. Berbeda dengan itu, CBT memiliki prosedur tersendiri bagi Peserta didik yang mengelami kendala teknis seperti yang ditemukan oleh peneliti dilapangan.

Peneliti membahas hal ini melalui hasil kuesioner berupa data demografi pada 30 Peserta didik yang peneliti ambil secara acak. Dari data yang diperoleh, peneliti mengambil simpulan data yang merupakan bagian dari hal-hal yang mampu mempengaruhi hasil Penilaian tengah semester SMK Islam Perti Jakarta. Untuk mengetahui seberapa besar pengaruh sistem CBT terhadap hasil PTS mata pelajaran matematika, maka peneliti menggunakan data kuesioner yang akan dianalisis yang 
dituangkan dalam deskriptif. Data yang akan dianalisis yakni data yang diperoleh dari hasil angket dan berupa soal-soal matematika yang diberikan di ujian yang bertujuan untuk mengetahui pengaruh CBT terhadap hasil PTS para Peserta didik yang diambil dari sampel penelitian.

Aplikasi Computer based test (CBT) yang digunakan untuk Ujian dan peserta didik dapat melakukan ujian dengan menggunakan sistem CBT yang dapat memudahkan guru dalam proses mengevaluasi hasil pembelajaran. Selain itu, dengan ujian menggunakan aplikasi CBT hasil koreksi dari jawaban ujian akan lebih objektif, cermat dan akurat, karena setelah ujian peserta didik dapat langsung melihat hasil ujian yang diperoleh pada ujian yang dilaksanakan (Lidya Wati et al., 2018). Selain itu, Computer-Based and Internet Delivered Testing is a development to highlight good practice issues and in relation to computer / Internet testing and testing. This guide addresses 4 major issues identified as key areas for ensuring good testing with computer / Internet testing: technology issues, quality issues, control issues and security issues (The International Test Commission, 2006).

\section{CONCLUSION}

Setelah melaksanakan penelitian mengenai Analisis penilaian tengah semester dengan menggunakan sistem CBT (Computer based test) mata pelajaran matematika Peserta didik SMK Islam Perti Jakarta, maka dapat disimpulkan: 1) Penggunaan CBT dalam penilaian tengah semester mata pelajaran mtematika di SMK Islam Perti Jakarta sangat bermanfaat, terutama dari segi efisiensi penggunaan kertas menjadi ujian berbasis CBT. 2) Penggunaan CBT dalam pembelajaran matematika khususnya mampu meningkatkan minat kepada peserta didik karena tampilan soal matematika yang cukup menarik dan dikerjakan melalui Handphone android masing-masing peserta didik, sehingga hasil penilaian tengah semester matematika ada peningkatan. 3) Penggunaan Computer based test (CBT) adalah solusi efektif untuk evaluasi pendidikan saat ini. Meskipun berbagai pendekatan dan sistem penilaian elektronik telah dikembangkan belakangan ini, namun kurangnya fungsionalitas waktu yang fleksibel, integritas hasil, penerapan, ketahanan dan skalabilitas serta kesalahan manusia adalah batasan utama dari platform yang ada. 4) Penggunaan CBT untuk PTS juga peneliti menemukan banyak permasalahan yang dihadapi oleh peserta didik, diantaranya koneksi internet peserta didik yang kurang optimal, mengakibatkan pengerjaan soal matematika Peserta didik menjadi terhambat. Selain itu, kendala-kendala teknis yang terjadi pada saat ujian PTS berlangsung seperti tidak muncul soal, waktu pengerjaan yang tidak sesuai, gambar tabel/simbol matematika yang tidak tampil di layar handphone peserta didik, lupa username dan password sehingga membuat pengerjaan ujian PTS matematika Peserta didik menjadi terganggu dan tidak maksimal.

Setelah penulis melakukan penelitian dengan mengamati, menguji, hingga mengambil simpulan dari hasil penelitian, maka penulis mengajukan saran sebagai berikut:

1) Bagi pihak sekolah diharapakan agar selalu memberi kesempatan pada Peserta didik lebih banyak mengenal setiap perkembangan teknologi, dan memberikan sosialisasi lebih banyak lagi dalam persiapan menghadapi ujian dengan system CBT (Computer Based Test)

2) Bagi pendidik diharapkan berperan aktif dalam memberikan latihan-latihan mengerjakan tugas dan ujian, serta memberikan stimulus yang positif agar Peserta didik tetap mempunyai minat belajar dan semangat menghadapi ujian PTS matematika. 
Peserta didik diharapkan dapat fokus pada proses pembelajaran matematika yang diberikan dan sering konsultasi dengan Pendidik mata pelajaran matematika agar mengetahui kemampuan Peserta didik sejauh mana mereka mampu mengerjakan soalsoal ujian matematika yang telah disipakan oleh Pendidik petugas ujian PTS dan mendapatkan nilai yang sangat memuaskan.

\section{REFERENCES}

Fagbola, T. M., Adigun, A. A., \& Oke, A. O. (2013). Computer-Based Test (CBT) System For University Academic Enterprise Examination. International journal of scientific \& technology research, 2(8), 336-342.

Harun Al-Rasyid. (2013). Analisis Standar Kualifikasi Akademik Guru SD di Kecamatan Kras Kabupaten Kediri. Widyagogik, 1(1), 1-16.

Hosseini, M., Abidin, M. J. Z., \& Baghdarnia, M. (2014). Comparability of Test Results of Computer based Tests (CBT) and Paper and Pencil Tests (PPT) among English Language Learners in Iran. Procedia - Social and Behavioral Sciences. https://doi.org/10.1016/j.sbspro.2014.03.465

Kadir, A. (2015). Menyusun Dan Menganalisis Tes Hasil Belajar. Jurnal Al-Ta'dib, 8(2), 70-81.

Lidya Wati, L., Kasmawi, K., \& Mawarni, S. (2018). Implementasi computer based test (CBT) di sekolah menengah kejuruan. Batoboh. https://doi.org/10.26887/bt.v3i1.491

Lutvaidah, U. (2016). Pengaruh Metode dan Pendekatan Pembelajaran terhadap Penguasaan Konsep Matematika. Formatif: Jurnal Ilmiah Pendidikan MIPA, 5(3), 279-285.

Nasrulloh, I., \& Ismail, A. (2018). Analisis Kebutuhan Pembelajaran Berbasis ICT. JURNAL PETIK, 3(1), 28.

Novrianti, N. (2014). Pengembangan Computer Based Testing (CBT) Sebagai Alternatif Teknik Penilaian Hasil Belajar. Lentera Pendidikan: Jurnal Ilmu Tarbiyah Dan Keguruan, 17(1), 34-42.

Putra, M. (2012). Domain Soal Pisa Untuk Literasi Matematika. Jurnal Peluang, 1(1), 28.

Sudibyo, L. (2011). Peranan dan Dampak Teknologi Informasi dalam Dunia Pendidikan di Indonesia. Widyatama, 20(2), 175-185.

Sudjana, N. (2013). Dasar-dasar proses belajar. Jurnal Pendidikan.

Suryadi, A. (2018). Perancangan Aplikasi Tes Berbasis Komputer (CBT) Menggunakan Pendekatan Terstruktur Untuk Penerimaan Mahasiswa Baru Di Perguruan Tinggi. Jurnal Petik, 1(1), 68.

Sutawidjaja, A., \& Afgani, J. (2015). Konsep Dasar Pembelajaran Matematika. Pembelajaran Matematika, 4(9), 51-57.

The International Test Commission. (2006). International Guidelines on Computer-Based and Internet-Delivered Testing. International Journal of Testing. https://doi.org/10.1207/s15327574ijt0602_4

Thurlow, M., Lazarus, S. S., Albus, D., \& Hodgson, J. (2010). Computer-based Testing : Practices and Considerations. Special Education, 55. 